\title{
Revascularization of tandem occlusions in acute ischemic stroke: review of the literature and illustrative case
}

\author{
Nnenna Mbabuike, MD, Kelly Gassie, MD, Benjamin Brown, MD, David A. Miller, MD, and \\ Rabih G. Tawk, MD \\ Department of Neurosurgery, Mayo Clinic, Jacksonville, Florida
}

\begin{abstract}
OBJECTIVE Tandem occlusions continue to represent a major challenge in patients with acute ischemic stroke (AIS). The anterograde approach with proximal to distal revascularization as well as the retrograde approach with distal to proximal revascularization have been reported without clear consensus or standard guidelines.
\end{abstract}

METHODS The authors performed a comprehensive search of the PubMed database for studies including patients with carotid occlusions and tandem distal occlusions treated with endovascular therapy. They reviewed the type of approach employed for endovascular intervention and clinical outcomes reported with emphasis on the revascularization technique. They also present an illustrative case of AIS and concurrent proximal cervical carotid occlusion and distal middle cerebral artery occlusion from their own experience in order to outline the management dilemma for similar cases.

RESULTS A total of 22 studies were identified, with a total of 790 patients with tandem occlusions in AIS. Eleven studies used the anterograde approach, 3 studies used the retrograde approach, 4 studies used both, and in 4 studies the approach was not specified. In the studies that reported Thrombolysis in Cerebral Infarction (TICI) grades, an average of $79 \%$ of patients with tandem occlusions were reported to have an outcome of $\mathrm{TICl} 2 \mathrm{~b}$ or better. One study found good clinical outcome in $52.5 \%$ of the thrombectomy-first group versus $33.3 \%$ in the stent-first group, as measured by the modified Rankin Scale (mRS). No study evaluated the difference in time to reperfusion for the anterograde and retrograde approach and its association with clinical outcome. The patient in the illustrative case had AIS and tandem occlusion of the internal carotid and middle cerebral arteries and underwent distal revascularization using a Solitaire stent retrieval device followed by angioplasty and stent treatment of the proximal cervical carotid occlusion. The revascularization was graded as $\mathrm{TICl}$ 2b; the postintervention National Institutes of Health Stroke Scale (NIHSS) score was 17, and the discharge NIHSS score was 7. The admitting, postoperative, and 30-day mRS scores were 5, 1, and 1, respectively.

CONCLUSIONS In stroke patients with tandem occlusions, distal to proximal revascularization represents a reasonable treatment approach and may offer the advantage of decreased time to reperfusion, which is associated with better functional outcome. Further studies are warranted to determine the best techniques in endovascular therapy to use in this subset of patients in order to improve clinical outcome.

https://thejns.org/doi/abs/10.3171/2017.1.FOCUS16521

KEY WORDS tandem occlusion; ischemic stroke; revascularization; endovascular therapy

$\mathrm{T}$ HE most recent trials regarding the acute management of stroke have highlighted that treatment with endovascular therapy is associated with better functional outcome at 90 days. ${ }^{23}$ Of the 5 recent stent retriever trials, all but one (SWIFT PRIME) included patients with proximal carotid artery stenosis or occlusion, yet the number of patients and exact technique of revascularization was not consistently reported. ${ }^{23}$ Outcome in this subgroup was reported in 2 trials (ESCAPE and MR CLEAN) to be promising, but the application of those results is limited by the heterogeneous setting in which the data were gathered. ${ }^{23}$ The anterograde method with proximal to distal revascularization and the retrograde method with distal to proximal revascularization have both been reported with little emphasis on relation between the technique used and functional outcome. There is clearly no unanimity in the

ABBREVIATIONS ACA = anterior cerebral artery; $\mathrm{AP}=$ anteroposterior; $\mathrm{AIS}=$ acute ischemic stroke; $\mathrm{CCA}=$ common carotid artery; $\mathrm{CTA}=\mathrm{CT}$ angiography; $\mathrm{DSA}=$ digital subtraction angiography; ICA = internal carotid artery; IV = intravenous; MCA = middle cerebral artery; $\mathrm{mRS}=$ modified Rankin Scale; NIHSS = National Institutes of Health Stroke Scale; $\mathrm{TICl}=$ Thrombolysis in Cerebral Infarction; tPA = tissue plasminogen activator.

SUBMITTED December 2, 2016. ACCEPTED January 26, 2017.

INCLUDE WHEN CITING DOI: 10.3171/2017.1.FOCUS16521. 
literature on the subject of the optimal strategy in regard to the technical approach to cases of stroke with tandem occlusions.

We present a review of the recent literature regarding tandem occlusions in acute ischemic stroke with a focus on the endovascular technique and related clinical outcome. We also present an illustrative case involving a patient with tandem occlusions of the cervical internal carotid artery (ICA) and middle cerebral artery (MCA) who was treated with distal to proximal revascularization.

\section{Literature Review Methods}

A search of the PubMed database identified all studies between 2011 and 2016 that included patients with tandem occlusions in AIS treated with endovascular therapy. Tandem occlusion was defined as a proximal carotid artery occlusion with concomitant distal intracranial occlusion. Anterograde therapy was defined as proximal to distal revascularization using stent placement and/or angioplasty of the proximal occlusion before distal revascularization. Distal revascularization techniques included stent retrieval, intra-arterial thrombolysis, microwire thrombus manipulation, or thromboaspiration. Retrograde therapy was defined as distal to proximal revascularization with the above methods applied in the reverse order (treatment of the distal occlusion before treatment of the proximal occlusion). The clinical outcome identified for each subset of patients was also recorded as defined by the respective studies.

\section{Results}

A review of the literature identified 22 studies that met the inclusion criteria. These studies involved a total of 837 patients, 805 of whom had AIS with tandem occlusion (Table 1). Eleven studies reported use of the anterograde approach, 3 studies used the retrograde approach, 4 studies used both, and in 4 studies the approach was not specified. Seventeen studies were single- and multicenter retrospective reviews and 1 was a prospective study. Twenty studies reported the TICI revascularization grade as a measure of clinical outcome, with an average grade of $2 \mathrm{~b}$ or 3 obtained in $79 \%$ of all cases for which TICI grade was reported (Table 1). The mRS was used as a primary outcome measure, and the majority of studies reported a $\mathrm{mRS}$ score of 2 or better in cases treated with endovascular therapy (Table 1).

Soize et al. ${ }^{27}$ reported a retrospective analysis of both tandem and solitary occlusions in AIS and demonstrated that tandem occlusions had a higher mortality rate at 3 months and more symptomatic intracranial hemorrhage at 24 hours. Duijsens et al. ${ }^{7}$ looked at tandem occlusions and further categorized them as true occlusions and pseudoocclusions (those with low flow). The authors identified 16 tandem occlusions on CTA, and in 15 of these 16 cases, the tandem occlusions were subsequently confirmed on digital subtraction angiography (DSA). Of the patients with true occlusions (10 patients), $60 \%$ had TICI $2 / 3,40 \%$ had TICI 0 , and $40 \%$ had an average NIHSS score at discharge of 3. Of the patients with pseudo-occlusions (6 pa- tients), $83 \%$ had a TICI $2 / 3$ or 3 after recanalization, and the average NIHSS score at discharge was 2.7

Throughout the literature, proximal revascularization consisted of stent placement and/or angioplasty for residual stenosis or passage of distal reperfusion devices. Distal revascularization was achieved with the MERCI retriever (Stryker), stent retrievers, Penumbra aspiration, balloon angioplasty and/or intracranial stent placement, and intraarterial thrombolysis. The majority of those performing the anterograde approach placed the proximal stent without distal protection due to the presence of the distal occlusion and did not use proximal flow arrest. ${ }^{5,13,15,20}$ Some studies reported sporadic cases of spontaneous distal recanalization following the placement of a stent in the proximal carotid occlusion. ${ }^{5,15}$

Only one study specifically advocated for the retrograde approach and included the specific cohort of carotid artery dissections in tandem occlusions. In this study, Marnat et al. found that only 25\% of patients with dissection required cervical stent placement, and no early ipsilateral stroke occurrence was found in those who did not have the stent placed. ${ }^{18}$ The authors advocated for a retrograde approach where intracranial revascularization is established before evaluation of circle of Willis insufficiency and making the decision to place a stent. Although they compared onset to puncture time between those with tandem and solitary occlusions, time to reperfusion was not specifically reported. ${ }^{18}$

Two studies compared the anterograde and retrograde approach. ${ }^{15,29}$ Stampfl et al. found that the mean time to reperfusion was 20 minutes longer in the anterograde approach. ${ }^{29}$ Lockau et al. had similar results, reporting a shorter median time from groin puncture to final reperfusion with the retrograde approach. ${ }^{15}$ Furthermore, for patients with tandem occlusions, Lockau et al. demonstrated good outcome (mRS score of 0-2) in 52.5\% of the thrombectomy-first group versus $33.3 \%$ in the stent-first group. Otherwise, the studies reporting use of the anterograde approach reported similar revascularization scores (Table 1).

While some studies mentioned the predictors of outcome with solitary occlusions, only one specifically addressed this in the cohort of tandem occlusions. Grigoryan et al. ${ }^{9}$ performed a multivariate analysis and found that the strongest predictor of good outcome in patients with tandem occlusions was young age and low presenting NIHSS score. Reperfusion score of TICI 3 and high ASPECTS (Alberta Stroke Program Early CT Score) at presentation were also found to have a strong association with good clinical outcome. Time to reperfusion was notably not specifically evaluated as a predictor of clinical outcome in the review of the literature.

\section{Illustrative Case}

\section{Presentation, Evaluation, and Initial Treatment}

This 72-year-old man presented to an outside facility with acute onset of right hemiparesis and aphasia within 3 hours of symptom onset. He was treated with intravenous administration of tissue plasminogen activator (tPA, Alteplase) after noncontrast $\mathrm{CT}$ of the head demonstrated a dense left middle cerebral artery (MCA) sign and no acute 
TABLE 1. Literature review of tandem occlusions

\begin{tabular}{|c|c|c|c|c|}
\hline Authors \& Year & $\begin{array}{l}\text { Level of } \\
\text { Evidence }\end{array}$ & $\begin{array}{l}\text { No. of Pts } \\
\text { w/ Tandem } \\
\text { Occlusions* }\end{array}$ & Treatment† & Description of Outcomes $\ddagger$ \\
\hline Malik et al., 2011 & $\begin{array}{l}3 \text {, retrospective, } \\
\text { single center }\end{array}$ & 77 & Anterograde & $\mathrm{TICl} \geq 2$ in $75.3 \% ; \mathrm{mRS} \leq 2$ in $41.6 \%$ at $3 \mathrm{mos}$ \\
\hline Machi et al., 2011 & 3 , retrospective & 10 & Retrograde & $\mathrm{TICl} 2 \mathrm{~b}$ or better in 8 of $10 \mathrm{pts}$; mRS 2 or better in 4 \\
\hline Kwak et al., 2013 & 3 , retrospective & 35 & Anterograde & $\begin{array}{l}\mathrm{TICl} 3,54.3 \% \text {; } \mathrm{TICl} 2 \mathrm{~b}, 20 \% \text {; } \mathrm{TICl} 2 \mathrm{a}, 25.7 \% \text {; mRS } 0-2 \text { at } 3 \text { mos, } \\
\text { 62.9\%; median NIHSS } 4 \text { at } 3 \text { mos (range } 1-17 \text { ) }\end{array}$ \\
\hline Dalyai et al., 2013 & 3 , retrospective & 17 & Anterograde & 94\% recanalization; $\S$ mean mRS 2.88 at discharge \\
\hline Soize et al., 2014 & 3 , prospective & $11 \rrbracket$ & $\begin{array}{l}\text { Retrograde approach } \\
\text { used "whenever } \\
\text { possible" }\end{array}$ & $\begin{array}{l}\text { Pts } w / \text { tandem occlusions had poorer functional outcomes than those } \\
\text { w/ solitary anterior circulation occlusions }(18.2 \% \text { vs } 67.7 \%, p= \\
\text { 0.01) \& higher mortality rate at } 3 \text { mos }(45.5 \% \text { vs } 12.9 \%, p=0.03)\end{array}$ \\
\hline Tütüncü et al., 2014 & $\begin{array}{l}3 \text {, retrospective } \\
\text { single center }\end{array}$ & $30 * *$ & Not specified & $\begin{array}{l}\mathrm{TICl} 2 \mathrm{~b} / 3 \text { in } 64 \% \text {; major neurological improvement†† in } 64 \% \text {; } \mathrm{mRS}<2 \\
\text { in } 54 \%\end{array}$ \\
\hline $\begin{array}{l}\text { Dababneh et al., } \\
2014\end{array}$ & $\begin{array}{l}3 \text {, retrospective } \\
\text { single center }\end{array}$ & 7 & Anterograde & $\begin{array}{l}\mathrm{TICl} 2 \mathrm{~b} / 3 \text { in } 6 \text { of } 7 \mathrm{pts} ; \mathrm{NIHSS} \leq 1 \text { at } 90 \text { days in } 4 \text { of } 7 ; \mathrm{mRS} 0 \text { at } 90 \\
\text { days in } 4 \text { of } 7\end{array}$ \\
\hline Stampfl et al., 2014 & $\begin{array}{l}3 \text {, retrospective, } \\
\text { single center }\end{array}$ & 24 & $\begin{array}{l}\text { Anterograde in } 21, \\
\text { retrograde in } 3\end{array}$ & $\mathrm{TICl} 2 \mathrm{~b}$ in $62.5 \%$; median mRS 3.0 at 3 mos \\
\hline Puri et al., 2015 & 3 , retrospective & 28 & $\begin{array}{r}\text { Anterograde in } 85.7 \% \text {, } \\
\text { retrograde in } 14.3 \%\end{array}$ & $\mathrm{TICl}$ 2a or better in $96.4 \% ; \mathrm{mRS} \leq 2$ in $52.5 \%$ at 3 mos \\
\hline $\begin{array}{l}\text { Duijsens et al., } \\
\quad 2015\end{array}$ & 3 , retrospective & $15 \ddagger \ddagger$ & Anterograde & $\begin{array}{l}\text { True occlusions: } \mathrm{TICl} 2 / 3 \text { in } 60 \% \text {; pseudo-occlusions: } \mathrm{TICl} 2 / 3 \text { in } \\
83 \% \text {; mean NIHSS } 3 \text { for true occlusions \& } 2 \text { for pseudo-occlusions }\end{array}$ \\
\hline Spiotta et al., 2015 & 3 , retrospective & 16 & Anterograde & $\mathrm{TICl} 2 / 3$ in $100 \%$; mRS $\leq 2$ at 3 mos in $56.3 \%$ \\
\hline Cohen et al., 2015 & 3 , retrospective & 24 & Anterograde & $\mathrm{TICl} 2 \mathrm{~b}$ in $79 \%$; $\mathrm{TICl} 2 \mathrm{a}$ in $13 \% ; \mathrm{TICl} 1$ in $8 \%$; mRS $\leq 276 \%$ at 3 mos \\
\hline Maurer et al., 2015 & 3 , retrospective & 43 & Not specified & $\mathrm{TICl} 2 \mathrm{~b} / 3$ in $76.7 \% ; \mathrm{mRS} \leq 2$ at discharge in $32.6 \%$ \\
\hline Lockau et al., 2015 & 3 , retrospective & 37 & $\begin{array}{l}\text { Retrograde in } 67.6 \% \\
\text { anterograde in } 32.4 \%\end{array}$ & $\begin{array}{l}\mathrm{TICl} 2 \mathrm{~b} / 3 \text { in } 73 \% \mathrm{w} / \text { anterograde } \mathrm{Tx} ; \mathrm{mRS} \leq 2 \text { at } 3 \text { mos in } 8.3 \% \text { of } \\
\text { anterograde cases vs } 16 \% \text {, retrograde }\end{array}$ \\
\hline Mishra et al., 2015 & 3 , retrospective & 7 & Anterograde & $\begin{array}{l}\mathrm{TICl} 2 \mathrm{~b} \text { in } 100 \% \text {; mean NIHSS } 4.9 \text { at discharge; mRS } 1 \text { at } 3 \text { mos in } \\
\quad 100 \%\end{array}$ \\
\hline $\begin{array}{l}\text { Heck \& Brown, } \\
2015\end{array}$ & $\begin{array}{l}3, \text { retrospective } \\
\text { single center }\end{array}$ & 23 & Anterograde & $\mathrm{TICl} 2 \mathrm{~b} / 3$ in $91 \% ; \mathrm{mRS} \leq 2$ at 3 mos in $52 \%$ \\
\hline Lescher et al., 2015 & 3 , retrospective & 39 & Not specified & $\mathrm{TICl} 2 \mathrm{~b}$ in $64 \% ; \mathrm{mRS} \leq 2$ at 3 mos in $36 \%$ \\
\hline Behme et al., 2015 & $\begin{array}{l}3 \text {, retrospective, } \\
\text { multicenter }\end{array}$ & 170 & $\begin{array}{l}\text { Anterograde in } 151 \\
\quad(89 \%)\end{array}$ & $\mathrm{TICl} 2 \mathrm{~b}$ in $77 \% ; \mathrm{TICl} 2 \mathrm{a}$ in $12 \% ; \mathrm{mRS} \leq 2$ at 3 mos in $36 \%$ \\
\hline Weiner et al., 2017 & $\begin{array}{l}\text { 4, case series } \\
\text { single center }\end{array}$ & 2 & Anterograde & Case 1: $\mathrm{TICl} 2 \mathrm{~b}, \mathrm{mRS} 1$ at 3 mos; Case 2: TICl 2b, mRS at 6 mos \\
\hline Marnat et al., 2016 & $\begin{array}{l}3, \text { retrospective } \\
\text { single center }\end{array}$ & 20 & Retrograde & $\mathrm{TICl} 2 \mathrm{~b} / 3$ in $70 \% ; \mathrm{mRS} \leq 2$ at 3 mos in $70 \%$ \\
\hline $\begin{array}{l}\text { Grigoryan et al., } \\
\quad 2016\end{array}$ & $\begin{array}{l}3 \text {, retrospective, } \\
\text { multicenter }\end{array}$ & 100 & $\begin{array}{l}\text { Anterograde \& retro- } \\
\text { grade but not speci- } \\
\text { fied per cases }\end{array}$ & $\mathrm{TICl} 2 \mathrm{~b} / 3$ in $88 \% ; \mathrm{mRS} \leq 2$ at 3 mos in $42 \%$ \\
\hline Fahed et al., 2016 & $\begin{array}{l}3 \text {, retrospective } \\
\text { single center }\end{array}$ & 70 & Not specified & mRS 2 or better in $50.8 \%$; $\mathrm{TICl} 2 \mathrm{~b} / 3$ in $67 \%$ \\
\hline
\end{tabular}

Ant $=$ anterior $;$ circ $=$ circulation $; \mathrm{EVT}=$ endovascular therapy; $\mathrm{Pts}=$ patients; $\mathrm{Tx}=$ treatment.

* Of 837 patients reported on in the listed papers, a total of 805 patients had tandem occlusions.

$\dagger$ Approach: 11 anterograde, 3 retrograde, 4 both, 4 did not specify.

$\ddagger$ Mean of $79 \% \mathrm{TICl} 2 \mathrm{~b}$ or better in studies that reported TICl grade.

$\S \mathrm{No} \mathrm{TICl}$ scores reported.

If In addition to the 11 patients with tandem occlusions, the authors also reported on 31 patients with solitary anterior circulation occlusions and compared outcomes.

** Of 30 patients with tandem occlusions, 14 were treated with EVT and 16 were treated with IV thrombolysis.

t† Decrease in NIHSS by 8 points or NIHSS of $1 / 0$ at discharge.

怙 Confirmed cases. One additional case was initially thought to be a tandem occlusion on presenting CTA and later seen as a solitary lesion on DSA. Of the original 16 cases, 10 involved true occlusions and 6 involved pseudo-occlusions. 
hemorrhage. Following transfer of the patient to our facility, he had a National Institutes of Health Stroke Scale (NIHSS) score of 20 and modified Rankin Scale (mRS) score of 5.

CT angiography (CTA) demonstrated left cervical ICA occlusion with reconstitution at the supraclinoid segment and occlusion within the left $\mathrm{M}_{1}$ segment of the MCA. A CT perfusion study demonstrated a large area of perfusion mismatch within the left MCA territory as defined by decreased blood flow and increased blood volume (Fig. 1). After discussion with the family, the decision was made to proceed with endovascular revascularization.

\section{Endovascular Technique}

The patient was placed under monitored anesthesia care (MAC) sedation. The right femoral artery was accessed, a 5-Fr catheter was advanced into the left common carotid artery (CCA), and angiographic runs confirmed proximal cervical carotid artery occlusion. The sheath and diagnostic catheter were exchanged for a 9-Fr sheath and a 9-Fr concentric balloon guide catheter, which was advanced into the left common carotid artery (CCA). A triaxial system was used with a 5MAX ACE reperfusion catheter (Penumbra), Marksman microcatheter (ev3/Covidien Vascular Therapies), and Glidewire Gold 0.016-inch-diameter microwire (Terumo) and navigated slowly and progressively into the occluded lumen of the ICA. The concentric balloon catheter was not inflated at this point. Serial arteriograms were obtained to insure that the endovascular devices remained within the intravascular lumen. Contrast injection at the level of the petrous ICA revealed filling of the anterior cerebral artery (ACA) territory with distal thrombus and a left $\mathrm{M}_{1}$ occlusion (Fig. 2). The microcatheter and microwire were navigated distal to the $\mathrm{M}_{1}$ occlusion, and the Penumbra 5MAX ACE catheter was advanced over the microcatheter and brought to the clot interface. A Solitaire FR device $(4 \times 20 \mathrm{~mm}$; Covidien, ev3 Neurovascular) was deployed and a Penumbra aspiration system was applied to the 5MAX ACE catheter. When it was seen that was there was no flow under aspiration, the catheter was removed under suction. Distal access was obtained again, and subsequent angiography revealed reperfusion of the MCA territory with a revascularization score of TICI $2 b$ with delayed filling in distal $\mathrm{M}_{3}$ branches (Fig. 3).

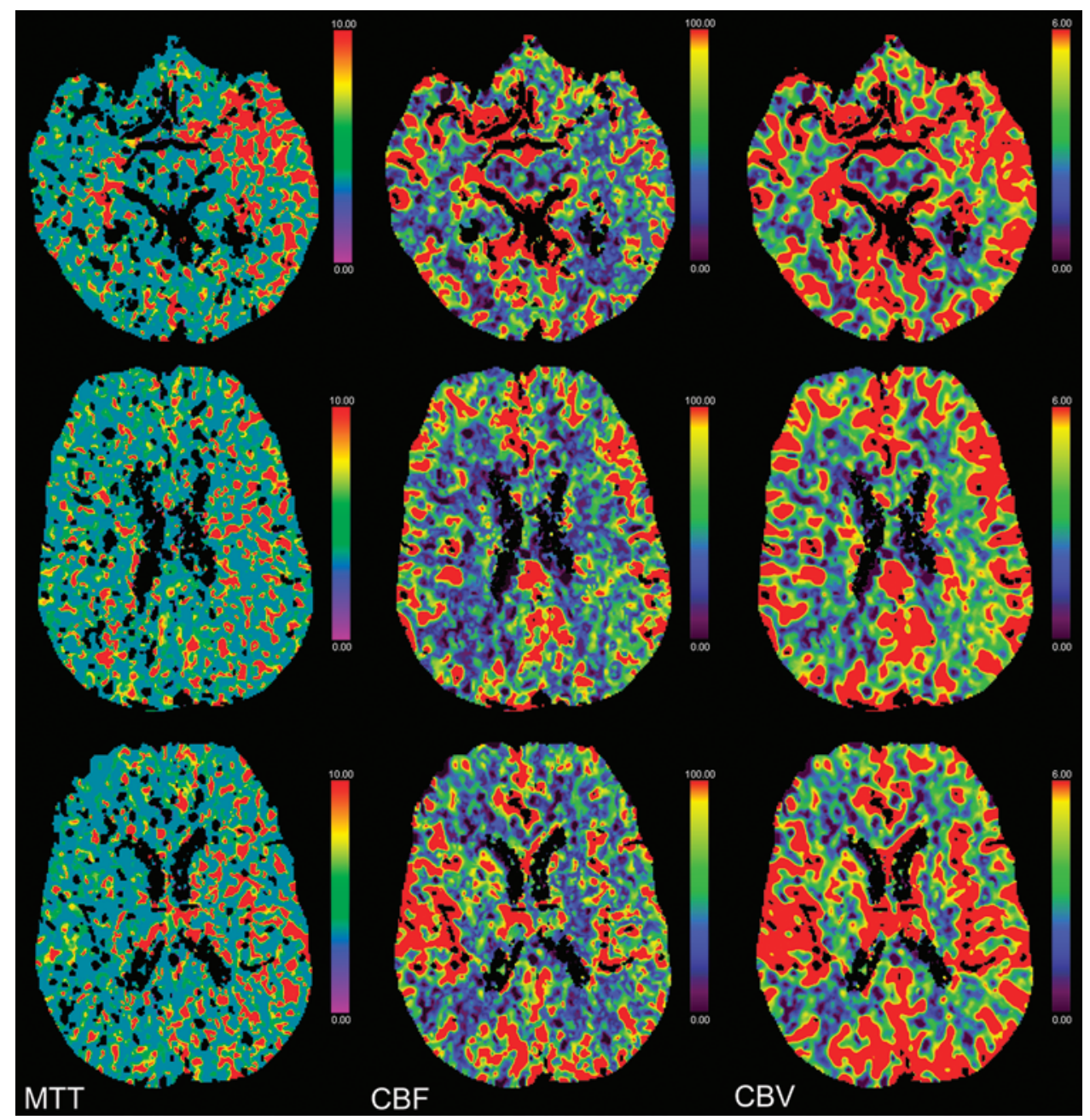

FIG. 1. Illustrative case. Images from CT perfusion study performed at presentation showing mean transit time (MTT), cerebral blood flow (CBF), and cerebral blood volume (CBV) demonstrating perfusion mismatch, with decreased CBF and increased CBV in the left MCA territory. 


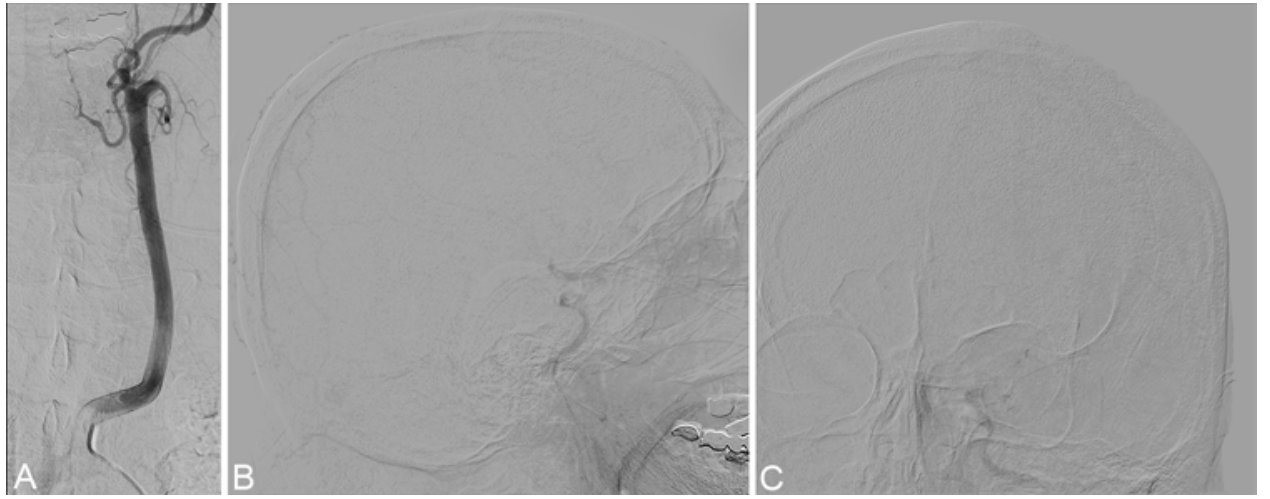

FIG. 2. Baseline angiography. A: Demonstration of occlusion in left CCA evidenced by stasis of contrast. B and C: Delayed lateral (B) and anteroposterior (AP) (C) sequence demonstrating delayed filling of the supraclinoid ICA with distal ICA occlusion.

To localize the distal extension of the ICA occlusion, the microcatheter was slowly and progressively withdrawn into the distal ICA with serial microinjections of contrast (Fig. 4A-C). Once the extent of the ICA occlusion was identified, we attempted thromboaspiration with the 5 MAX ACE, but the attempt was not successful. The Traxcess microwire (MicroVention) extension was added to maintain access, and the microcatheter was exchanged with an Aviator plus balloon dilatation catheter $(4 \times 20$ $\mathrm{mm}$, Cordis) for angioplasty of the area of focal stenosis under proximal flow arrest to prevent distal embolization. Next, a carotid Wallstent endoprosthesis $(8 \times 21 \mathrm{~mm}$, Boston Scientific Corp.) was deployed across the area with abnormal lumen. Postdilatation angioplasty was performed for approximately $50 \%$ residual stenosis.

The patient's blood pressure was in the $200 \mathrm{~mm} \mathrm{Hg}$ range and left untreated until this point to help with collateral circulation before recanalization. Members of the anesthesia department administered intravenous (IV) antihypertensive treatment at this time to lower the systolic blood pressure. To reduce the risk of hemorrhagic conversion after recanalization, several aspirations were performed to remove debris, and once the systolic blood pressure was less than $160 \mathrm{~mm} \mathrm{Hg}$, the concentric proxi- mal balloon was deflated. A subsequent cervical angiogram showed revascularization of the cervical ICA (Fig. $4 \mathrm{D}$ and $\mathrm{E}$ ) and a cerebral angiogram showed thrombosis in the distal $\mathrm{A}_{3}$ segment (Fig. 5A and B). The triaxial system was navigated into the $\mathrm{A}_{2}$ segment just proximal to the site of occlusion. The Marksman microcatheter was exchanged for a 3MAX reperfusion catheter (Penumbra). The Neuron 3MAX separator (Penumbra) was used for thrombus manipulation and a total of $4 \mathrm{mg}$ of tissue plasminogen activator (tPA) was administered intra-arterially. Final control cerebral angiogram showed recanalization of the $\mathrm{A}_{3}$ segment from a TICI grade of 0 to a TICI grade of 3 and maintained patency of the MCA territory with a TICI grade of $2 \mathrm{~b}$ (Fig. 5C-E).

An 8-Fr Angio-Seal (Terumo Interventional Systems) was applied to the groin for closure. The patient was given aspirin $325 \mathrm{mg}$ during the procedure and intravenous heparin was administered to maintain an activated clotting time (ACT) greater than 250 seconds.

\section{Postoperative Course}

CT showed hyperdensity within the left basal ganglia, internal capsule, thalamus, and areas in the left MCA re-
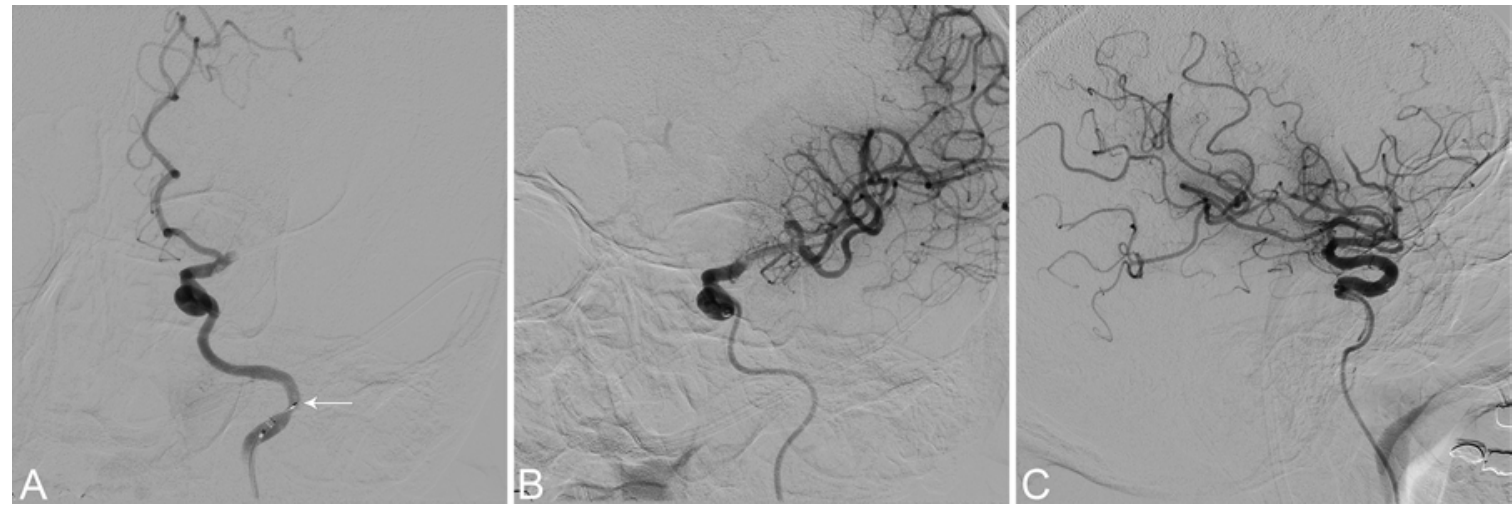

FIG. 3. Distal revascularization. A: Left ICA injection angiogram, AP view, obtained after navigation of triaxial system with Gold 0.016 -inch-diameter microwire leading (white arrow) into petrous ICA segment. The image demonstrates left $M_{1}$ segment occlusion and filling of left ACA territory. B and C: Left ICA injection angiograms (AP [B] and lateral [C] views) obtained after Penumbra aspiration and Solitaire retrieval of thrombus demonstrating reperfusion of the MCA territory with a revascularization score of TICl $2 \mathrm{~b}$ with delayed filling in the distal $\mathrm{M}_{3}$ branches. 


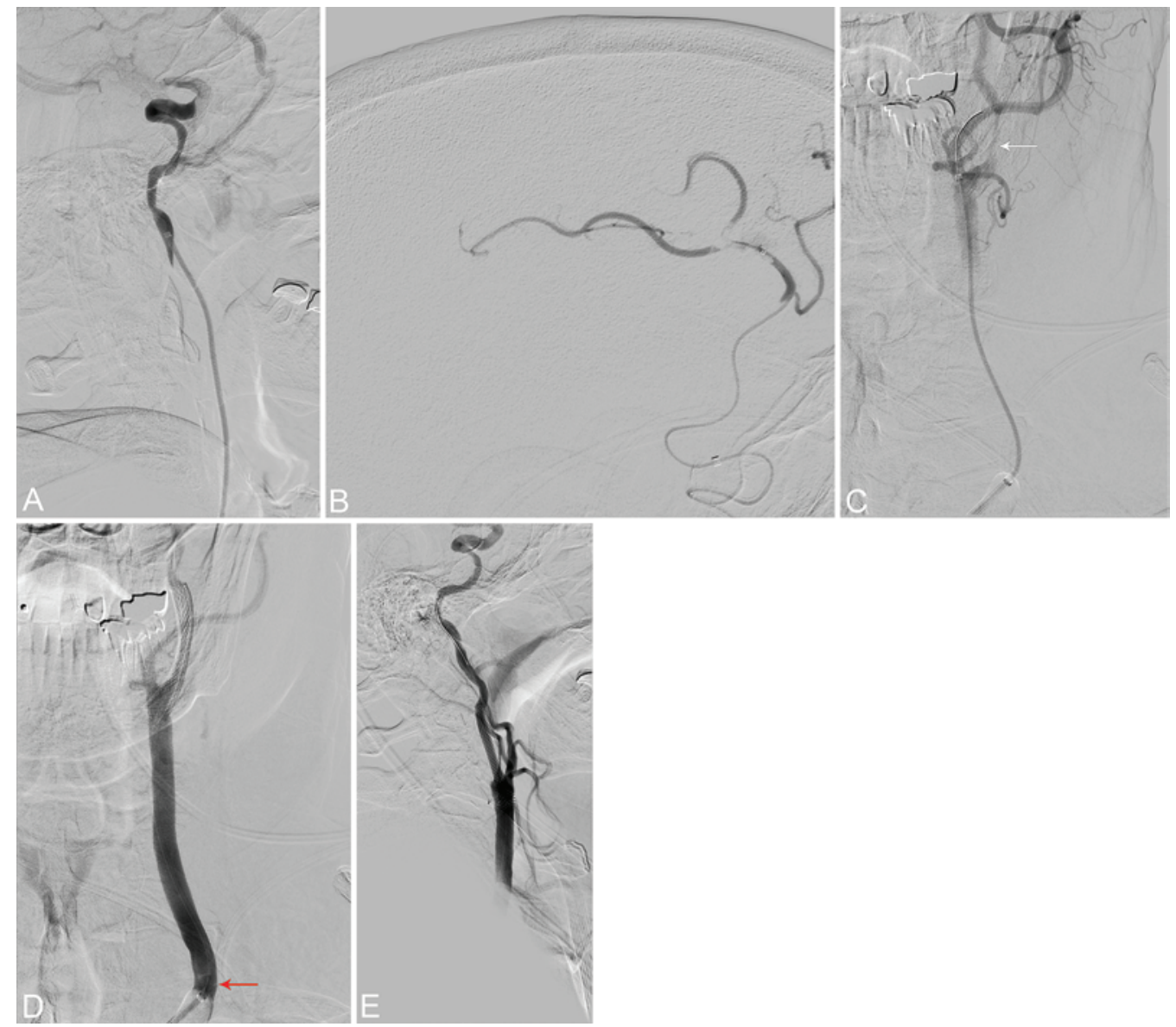

FIG. 4. Proximal revascularization. A-C: Serial left ICA injection angiograms (lateral view) obtained with progressive withdrawal of microcatheter demonstrating the level of proximal occlusion in the cervical ICA (white arrow). D and E: Left CCA injection angiograms (AP and lateral views) showing successful deployment of a carotid WallStent across focal cervical ICA stenosis. Note the inflation of the proximal balloon catheter from proximal flow arrest (red arrow).

gion in the posterior frontal and parietal cortex (Fig. 6A). The patient was maintained on aspirin at $325 \mathrm{mg}$ and IV heparin over 24 hours with an activated partial thromboplastin time (aPTT) goal of 40-50 seconds. Subsequent CT scans demonstrated clearance of hyperdensity that appeared to be contrast staining, and treatment with clopidogrel was initiated. The IV heparin was discontinued once the clopidogrel treatment was started, and the patient was maintained on clopidogrel and aspirin (Fig. 6B and C).

The immediate follow-up NIHSS score was 17. Carotid artery Doppler ultrasonography confirmed stent patency, and the patient was discharged to rehabilitation on Day 4 with an NIHSS score of 7 and an mRS score of 1. At 30day follow-up, the patient still had an mRS score of 1 with only minimal residual aphasia.

\section{Discussion}

As techniques for endovascular revascularization evolve, there is uncertainty as to how to approach tandem occlusions in AIS. The literature suggests that tandem occlusions are associated with worse outcome than solitary intracranial occlusions. Historically, patients with tandem occlusions have had a mortality rate ranging between $24 \%$ and $27 \%$ and a good clinical outcome measured by an mRS of $0-2$ in only $10 \%-29 \%$ of cases. ${ }^{12,25}$ Intravenous thrombolysis in these patients has not demonstrated a significant difference in recanalization rates or clinical outcome in comparison with placebo. ${ }^{6}$ More recently, despite the recognized poor clinical outcome, it has been suggested through systematic reviews that these patients may fare better with endovascular management. ${ }^{11,21}$ Although we have used both approaches at our center, we are not certain about the best practice in similar cases, and the reported literature on this topic has no established recommendations.

Furthermore, the underlying pathology is variable, and proximal occlusions can be related to a wide spectrum of disorders, such as dissections, atherosclerotic occlusions, embolic events, or even occlusions in patients who have previously undergone carotid artery stent placement. In a review of recent stroke studies in the American Heart Association/American Stroke Association guidelines update, ${ }^{23}$ Powers et al. report that 30 of the 75 patients with carotid artery stenosis or occlusion in MR CLEAN were treated with stent placement during the acute intervention. ${ }^{23}$ Nine of the 19 patients with carotid occlusion in REVASCATS had stents placed at the time of thrombectomy. ${ }^{23}$ However, 

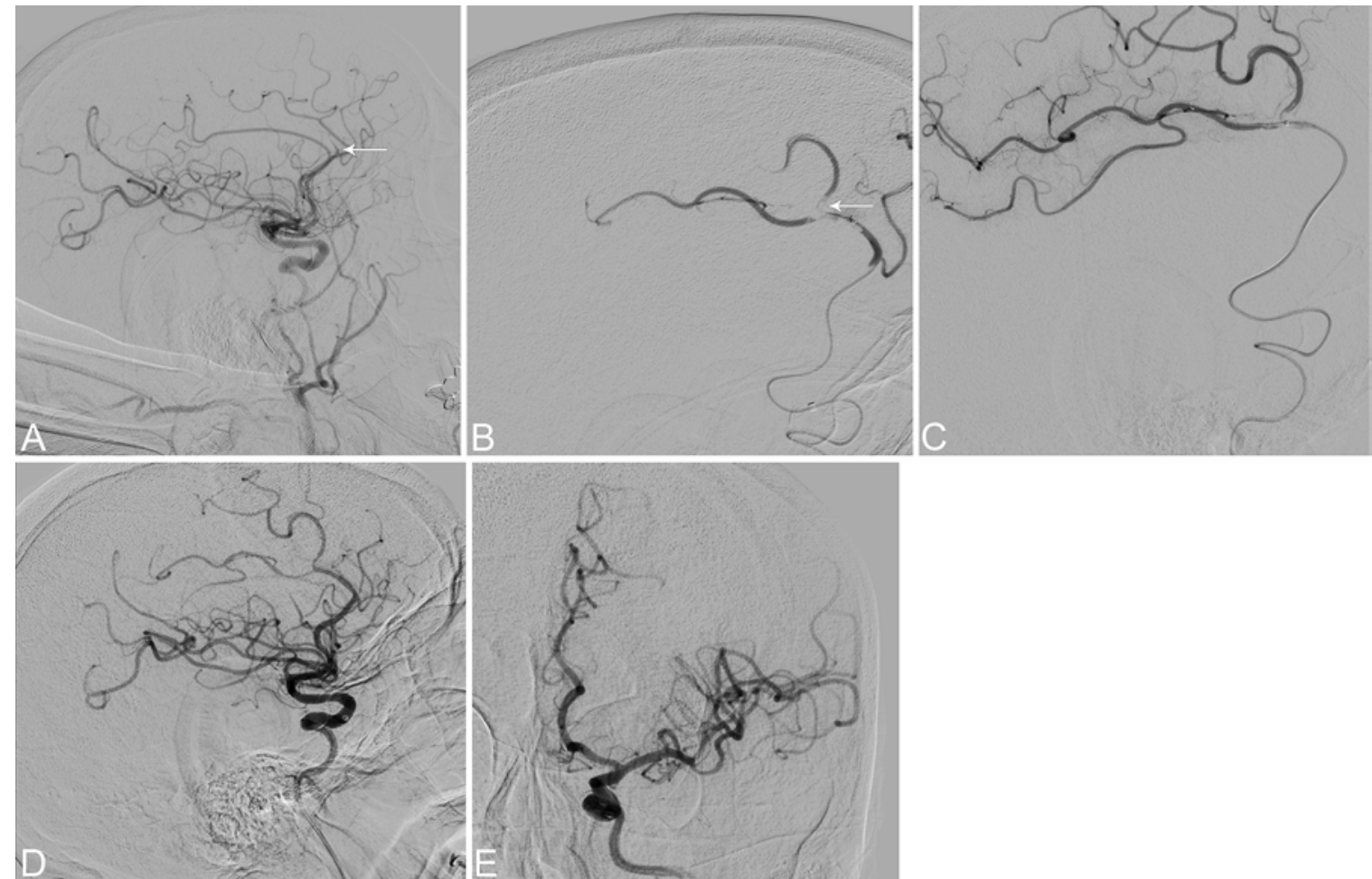

FIG. 5. Revascularization of ACA. A: Left ICA injection (lateral view) angiogram obtained after placement of stent demonstrating distal $\mathrm{A}_{3}$ segment thrombosis (white arrow). B: Microcatheter angiogram demonstrating thrombus at $\mathrm{A}_{2}$ segment bifurcation and occlusion of distal ACA branches (white arrow). C: Left ICA injection (lateral view) angiogram obtained after microwire thrombus manipulation and intra-arterial tPA treatment showing $\mathrm{TICI} 3$ revascularization of the ACA territory. D and E: Left ICA injection final control angiograms (lateral $[D]$ and $A P[E]$ views) showing $\mathrm{TICl} 3$ revascularization of the ACA territory and $\mathrm{TICl} 2 \mathrm{~b}$ revascularization of the MCA territory.

it was not made clear what factors were considered regarding the decision to place a stent and what approach was used (anterograde versus retrograde revascularization) to recanalize the proximal and distal occlusions.
We noted that the majority of published approaches involved anterograde revascularization of the proximal carotid occlusion with angioplasty and/or stent placement followed by distal revascularization of the intracranial le-
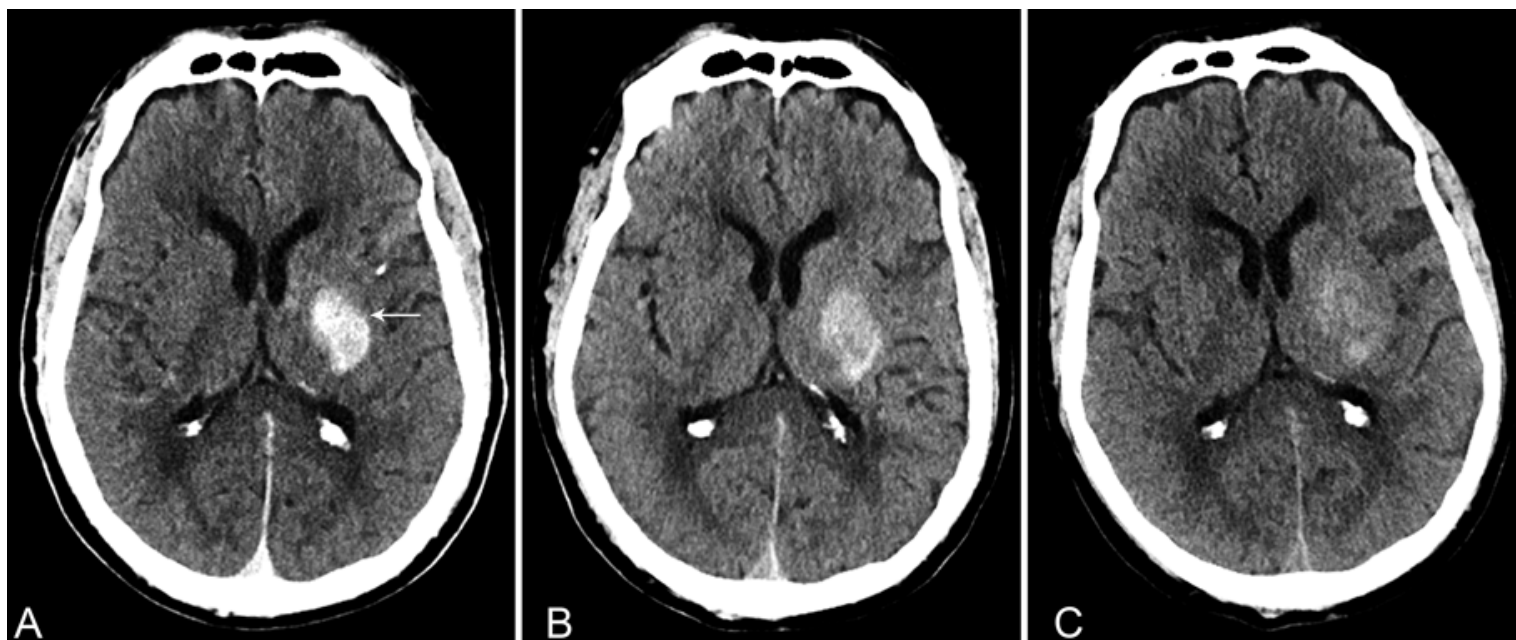

FIG. 6. Postintervention axial noncontrast CT image. A: Image from scan performed immediately after intervention showing hyperdensity in the putamen, globus pallidus (white arrow), internal capsule, and thalamus. Areas of hyperdensity were also seen in regions of the posterior frontal cortex and parietal cortex supplied by the left MCA (not shown here). B and C: Images from scans performed 6 hours (B) and 24 hours (C) after intervention showing resolution of likely contrast staining in the area of the left basal ganglia. 
sion (Table 1). The cited advantages included the ability to jail the likely atheromatous friable plaque against the vessel wall proximally with angioplasty and/or stent placement, preventing showering of emboli distally. Additionally, the recanalization of the proximal occlusion results in anterograde blood flow and is thought to assist in thrombolysis for the distal lesion.

Previously published anterograde approaches involved an assessment of the intracranial circulation for improved flow after revascularization of the proximal occlusion. The time required for stent placement and/or angioplasty in combination with the time to assess for distal occlusions could certainly delay intracranial reperfusion that could be obtained from distal collateral circulation across the circle of Willis and may contribute to neurological morbidity and worse functional outcome. Moreover, proximal revascularization can result in embolism of thrombus distally to a branch that was not occluded, highlighting the importance of using proximal protection in these cases. ${ }^{22}$

Decreasing "door to needle time" and time to reperfusion represents a driving force in establishing stroke management guidelines. ${ }^{23} \mathrm{~A}$ recent meta-analysis looked at the relationship between time to treatment and endovascular intervention, and time to treatment was defined as the time from symptom onset to time of reperfusion (TICI $2 \mathrm{~b}$ or 3 ). The rate of functional independence was $64 \%$ with reperfusion at 3 hours and $46 \%$ with reperfusion at 8 hours. ${ }^{26}$

As in our illustrative case, and in cases with proximal and distal tandem occlusions with patency of the carotid terminus and proximal intracranial segments on CTA, we prefer to perform a distal to proximal approach for revascularization. In this specific subset of patients, we believe that revascularization could be obtained faster from distal collaterals, and this might be associated with reduced time to recanalization and possibly a better outcome. As previously mentioned, Lockau et al..$^{15}$ reported a higher rate of good outcome for patients with tandem occlusions when distal thrombectomy was performed first rather than stent placement first (52.5\% vs $33.3 \%$ ). However, their study was retrospective, with inherent selection bias.

Although future studies can be designed to compare the time to reperfusion for these 2 approaches, technical nuances should be established, and care should be individualized based on the specifics of the underlying pathology. For example, occlusions that involve the carotid terminus and extend proximally with no underlying pathology of the cervical ICA might be better addressed with proximal flow arrest regardless of technique for clot retrieval to prevent distal embolization. Even large suction catheters are not guaranteed to remove the clot without leaving pieces that can be displaced after restoration of flow. Clots can be moved distally to more important branches, and stroke cases can be converted from ischemic penumbra of noneloquent brain to infarct of highly functional and eloquent brain with irreversible damage.

Additionally, technical considerations exist along with significant differences in these approaches. When deploying a stent in the proximal ICA first, there is an advantage to establishing a true lumen for navigation of reperfusion devices distally. However, there is the possibility of challenges for stent deployment, and some stents with open-cell design can compromise the ability to advance the reperfusion devices distally. Stent retrievers can also get caught on the stent if not retrieved distally. All of this can potentially prolong the time to distal revascularization and might increase the morbidity of these challenging procedures. In our center, we try to avoid the use of stents in the carotid artery unless there is a dissection flap that could not be maintained open or a clot that could not be aspirated. We attempt balloon angioplasty first to allow for advancement of a large suction catheter with the microcatheter and microwire. In our practice we use proximal protection with flow arrest at the ICA if possible to reduce the risk of distal embolization. The balloon is inflated in the CCA in occlusions at the bifurcation, and this strategy may still allow for retrograde flow through the external carotid artery.

Hemorrhagic conversion is also a recognized potential complication of acute stroke treatment, and the risk is magnified in the setting of stent and/or angioplasty requiring dual antiplatelet therapy regardless of anterograde or retrograde approach. For the studies evaluated in this review, the rate of symptomatic intracranial hemorrhage among patients treated for tandem occlusions ranged from $0 \%-18 \%$ but was not specifically evaluated as a predictor of clinical outcome. ${ }^{9,11}$ This risk can be minimized by ensuring a normotensive blood pressure before restoration of flow and following the procedure. As mentioned above, we try to avoid stent placement whenever possible, and the decision of whether or not to use a stent is delayed until after attempts of revascularization of distal occlusions. When stent deployment is necessary, we maintain patients on aspirin and intravenous heparin with low PTT goal (40-60) and perform serial CT imaging to rule out acute hemorrhagic conversion before administering a loading dose of clopidogrel.

Currently, the combination of angioplasty and stent placement for proximal stenosis or occlusion is not considered useful in the most recent American Heart Association guidelines on management of patients with AIS (Class IIB; Level of Evidence C). ${ }^{23}$ The use of carotid artery stents placement in acute stroke is considered an "off-label" application and is not covered by the Centers for Medicare and Medicaid Services (CMS) guidelines in regard to national indications for coverage in percutaneous transluminal angioplasty (PTA). Specifically, patients who have had a disabling stroke (mRS score $\geq 3$ ) shall be excluded from coverage. ${ }^{2}$ We have not used carotid artery stent placement routinely in the acute setting, and we usually avoid using stents in this setting given the need for dual anticoagulation and risk of hemorrhagic conversion. However, we have found angioplasty helpful in patients with severe underlying ICA stenosis that likely progressed and caused the occlusion. In patients with a dissection flap in whom a patent ICA cannot be maintained or in those with a large thrombus that we cannot aspirate, we use a stent as a method of maintaining patency of the pathological ICA segment, as the stent pushes the dissecting flap or the clot outside and helps reestablish flow within the lumen.

This study has several limitations. The majority of studies included in the literature review represent Level 
3 evidence with heterogeneous and nonstandardized description of the specific endovascular technique of revascularization. Together with the illustrative case, this review calls for the need to better individualize techniques to specific cases of tandem occlusions and perhaps establish recommendations based on clinical outcome.

\section{Conclusions}

Distal to proximal revascularization of tandem occlusions is worth a special consideration, especially in patients with patent collaterals through the circle of Willis. Compared with the anterograde approach, this technique may result in better clinical outcomes, especially with evidence that time to reperfusion is a significant predictor of functional outcome. Technical variations should be individualized to the specific distribution and configuration of the occlusions, as tandem occlusions have not been analyzed systematically in the most recent stroke trials. Future studies involving the endovascular management of these patients may be able to further elucidate the predictors of good clinical outcome in this group.

\section{References}

1. Behme D, Mpotsaris A, Zeyen P, Psychogios MN, Kowoll A, Maurer CJ, et al: Emergency stenting of the extracranial internal carotid artery in combination with anterior circulation thrombectomy in acute ischemic stroke: a retrospective multicenter study. AJNR Am J Neuroradiol 36:2340-2345, 2015

2. Centers for Medicare \& Medicaid Services: National Coverage Determination (NCD) for Percutaneous Transluminal Angioplasty (PTA) (20.7). Baltimore: Centers for Medicare \& Medicaid Services, 2016 (https://www.cms.gov/medicarecoverage-database/details/ncd-details.aspx?NCDId=201) [Accessed February 14, 2017]

3. Cohen JE, Gomori JM, Rajz G, Itshayek E, Eichel R, Leker RR: Extracranial carotid artery stenting followed by intracranial stent-based thrombectomy for acute tandem occlusive disease. J Neurointerv Surg 7:412-417, 2015

4. Dababneh H, Bashir A, Hussain M, Guerrero WR, Morgan W, Khanna AY, et al: Endovascular treatment of tandem internal carotid and middle cerebral artery occlusions. J Vasc Interv Neurol 7:26-31, 2014

5. Dalyai RT, Chalouhi N, Singhal S, Jabbour P, Gonzalez LF, Dumont AS, et al: Stent-assisted endovascular recanalization of extracranial internal carotid artery occlusion in acute ischemic stroke. World Neurosurg 79:143-148, 2013

6. De Silva DA, Brekenfeld C, Ebinger M, Christensen S, Barber PA, Butcher KS, et al: The benefits of intravenous thrombolysis relate to the site of baseline arterial occlusion in the Echoplanar Imaging Thrombolytic Evaluation Trial (EPITHET). Stroke 41:295-299, 2010

7. Duijsens HM, Spaander F, van Dijk LC, Treurniet FE, Keunen RW, Mosch A, et al: Endovascular treatment in patients with acute ischemic stroke and apparent occlusion of the extracranial internal carotid artery on CTA. J Neurointerv Surg 7:709-714, 2015

8. Fahed R, Redjem H, Blanc R, Labreuche J, Robert T, Ciccio $\mathrm{G}$, et al: Endovascular management of acute ischemic strokes with tandem occlusions. Cerebrovasc Dis 41:298-305, 2016

9. Grigoryan M, Haussen DC, Hassan AE, Lima A, Grossberg J, Rebello LC, et al: Endovascular treatment of acute ischemic stroke due to tandem occlusions: large multicenter series and systematic review. Cerebrovasc Dis 41:306-312, 2016

10. Heck DV, Brown MD: Carotid stenting and intracranial thrombectomy for treatment of acute stroke due to tandem occlusions with aggressive antiplatelet therapy may be associated with a high incidence of intracranial hemorrhage. J Neurointerv Surg 7:170-175, 2015

11. Kappelhof M, Marquering HA, Berkhemer OA, Majoie CBLM: Intra-arterial treatment of patients with acute ischemic stroke and internal carotid artery occlusion: a literature review. J Neurointerv Surg 7:8-15, 2015

12. Kimura K, Iguchi Y, Shibazaki K, Iwanaga T, Aoki J: Recanalization of the MCA should play an important role in dramatic recovery after t-PA therapy in patients with ICA occlusion. J Neurol Sci 285:130-133, 2009

13. Kwak HS, Hwang SB, Jin GY, Hippe DS, Chung GH: Predictors of functional outcome after emergency carotid artery stenting and intra-arterial thrombolysis for treatment of acute stroke associated with obstruction of the proximal internal carotid artery and tandem downstream occlusion. AJNR Am J Neuroradiol 34:841-846, 2013

14. Lescher S, Czeppan K, Porto L, Singer OC, Berkefeld J: Acute stroke and obstruction of the extracranial carotid artery combined with intracranial tandem occlusion: results of interventional revascularization. Cardiovasc Intervent Radiol 38:304-313, 2015

15. Lockau H, Liebig T, Henning T, Neuschmelting V, Stetefeld $\mathrm{H}$, Kabbasch C, et al: Mechanical thrombectomy in tandem occlusion: procedural considerations and clinical results. Neuroradiology 57:589-598, 2015

16. Machi P, Lobotesis K, Maldonado IL, Costalat V, Vendrell JF, Riquelme C, et al: Endovascular treatment of tandem occlusions of the anterior cerebral circulation with solitaire FR thrombectomy system. Initial experience. Eur J Radiol 81:3479-3484, 2012

17. Malik AM, Vora NA, Lin R, Zaidi SF, Aleu A, Jankowitz BT, et al: Endovascular treatment of tandem extracranial/intracranial anterior circulation occlusions: preliminary singlecenter experience. Stroke 42:1653-1657, 2011

18. Marnat G, Mourand I, Eker O, Machi P, Arquizan C, Riquelme C, et al: Endovascular management of tandem occlusion stroke related to internal carotid artery dissection using a distal to proximal approach: insight from the RECOST study. AJNR Am J Neuroradiol 37:1281-1288, 2016

19. Maurer CJ, Joachimski F, Berlis A: Two in one: endovascular treatment of acute tandem occlusions in the anterior circulation. Clin Neuroradiol 25:397-402, 2015

20. Mishra A, Stockley H, Goddard T, Sonwalker H, Wuppalapati S, Patankar T: Emergent extracranial internal carotid artery stenting and mechanical thrombectomy in acute ischaemic stroke. Interv Neuroradiol 21:205-214, 2015

21. Mokin M, Kass-Hout T, Kass-Hout O, Dumont TM, Kan P, Snyder KV, et al: Intravenous thrombolysis and endovascular therapy for acute ischemic stroke with internal carotid artery occlusion: a systematic review of clinical outcomes. Stroke 43:2362-2368, 2012

22. Omran J, Mahmud E, White CJ, Aronow HD, Drachman DE, Gray W, et al: Proximal balloon occlusion versus distal filter protection in carotid artery stenting: a meta-analysis and review of the literature. Catheter Cardiovasc Interv [epub ahead of print], 2016

23. Powers WJ, Derdeyn CP, Biller J, Coffey CS, Hoh BL, Jauch EC, et al: 2015 American Heart Association/American Stroke Association Focused Update of the 2013 Guidelines for the Early Management of Patients with Acute Ischemic Stroke Regarding Endovascular Treatment: a Guideline for Healthcare Professionals from the American Heart Association/ American Stroke Association. Stroke 46:3020-3035, 2015

24. Puri AS, Kühn AL, Kwon HJ, Khan M, Hou SY, Lin E, et al: Endovascular treatment of tandem vascular occlusions in acute ischemic stroke. J Neurointerv Surg 7:158-163, 2015

25. Rubiera M, Ribo M, Delgado-Mederos R, Santamarina E, 
Delgado P, Montaner J, et al: Tandem internal carotid artery/ middle cerebral artery occlusion: an independent predictor of poor outcome after systemic thrombolysis. Stroke 37:23012305,2006

26. Saver JL, Goyal M, van der Lugt A, Menon BK, Majoie CBLM, Dippel DW, et al: Time to treatment with endovascular thrombectomy and outcomes from ischemic stroke: a meta-analysis. JAMA 316:1279-1288, 2016

27. Soize S, Kadziolka K, Estrade L, Serre I, Barbe C, Pierot L: Outcome after mechanical thrombectomy using a stent retriever under conscious sedation: comparison between tandem and single occlusion of the anterior circulation. J Neuroradiol 41:136-142, 2014

28. Spiotta AM, Lena J, Vargas J, Hawk H, Turner RD, Chaudry MI, et al: Proximal to distal approach in the treatment of tandem occlusions causing an acute stroke. J Neurointerv Surg 7:164-169, 2015

29. Stampfl S, Ringleb PA, Möhlenbruch M, Hametner C, Herweh C, Pham M, et al: Emergency cervical internal carotid artery stenting in combination with intracranial thrombectomy in acute stroke. AJNR Am J Neuroradiol 35:741-746, 2014

30. Tütüncü S, Scheitz JF, Bohner G, Fiebach JB, Endres M, Nolte $\mathrm{CH}$ : Endovascular procedures versus intravenous thrombolysis in stroke with tandem occlusion of the anterior circulation. J Vasc Interv Radiol 25:1165-1170, 2014
31. Weiner GM, Feroze R, Panczykowski DM, Aghaebrahim A, Ares W, Agarwal N, et al: Endovascular treatment of tandem common carotid artery origin and distal intracranial occlusion in acute ischemic stroke. World Neurosurg 97:360365,2017

\section{Disclosures}

Dr. Tawk reports direct stock ownership in Medtronic.

\section{Author Contributions}

Acquisition of data: Tawk, Brown, Miller. Analysis and interpretation of data: Mbabuike, Gassie. Drafting the article: Mbabuike. Critically revising the article: Tawk. Reviewed submitted version of manuscript: Tawk. Approved the final version of the manuscript on behalf of all authors: Tawk. Administrative/technical/ material support: Gassie, Brown, Miller. Study supervision: Tawk, Brown, Miller.

\section{Correspondence}

Rabih G. Tawk, Department of Neurosurgery, Mayo Clinic, 4500 San Pablo Rd. South, Jacksonville, FL 32224. email: tawk.rabih@ mayo.edu. 